\title{
Standalone Tensile Testing of Thin Film Materials for MEMS/NEMS Applications
}

\author{
Arash Tajik and Hamid Jahed \\ University of Waterloo \\ Canada
}

\section{Introduction}

The microelectronics industry has been consistently driven by the scaling roadmap, colloquially referred to as the Moore's law. Consequently, during the past decades, integrated circuits have scaled down further. This shrinkage could have never been possible without the efficient integration and exploitation of thin film materials.

Thin film materials, on the other hand, are the essential building blocks of the micro- and nano-electromechanical systems (MEMS and NEMS). Utilization of thin film materials provides a unique capability of further miniaturizing electromechanical devices in microand nano-scale. These devices are the main components of many sensors and actuators that perform electrical, mechanical, chemical, and biological functions. In addition to the wide application of thin film materials in micro- and nano-systems, this class of materials has been historically utilized in optical components, wear resistant coatings, protective and decorative coatings, as well as thermal barrier coatings on gas turbine blades.

In some applications, thin film materials are used mainly as the load-bearing component of the device. Microelectromechanical systems (MEMS) are the example of these applications. Thin film materials carry mechanical loads in thermal actuators, switches and capacitors in RF MEMS, optical switches, micro-mirror hinges, micro-motors, and many other miniaturized devices. In these applications, one of the main criteria to choose a specific material is its ability to perform the mechanical requirements. Therefore, a clear understanding of the mechanical behavior of thin film materials is of great importance in these applications. This understanding helps better analyze the creep in thermal actuators (Tuck et al., 2005; Paryab et al., 2006), to investigate the fatigue of polysilicon (Mulhstein et al., 2001; Shrotriya et al., 2004) and metallic micro-structures (Eberl et al., 2006; Larsen et al., 2003), to scrutinize the relaxation and creep behavior of switches made of aluminum (Park et al., 2006; Modlinski et al., 2004) and gold films (Gall et al., 2004), to study the hinge memory effect (creep) in micro-mirrors (Sontheimer, 2002), and to address the wear issues in micro-motors. (van Spengen, 2003)

In some other applications, the thin film material is not necessarily performing a mechanical function. However, during the fabrication process or over the normal life, the device experiences mechanical loads and hence may suffer from any of the mechanical failure issues. Examples of these cases are the thermal fatigue in IC interconnects (Gudmundson \& Wikstrom, 2002), strain ratcheting in passivated films (Huang et al., 2002; He et al., 2000), the 
fracture and delamination of thin films on flexible substrates (Li \& Suo, 2006), the fracture of porous low-k dielectrics (Tsui et al., 2005), electromigration (He et al., 2004), the chippackage-interaction (CPI) (Wang \& Ho, 2005), and thin film buckling and delamination (Sridhar et al., 2001).

In order to address the above-mentioned failure issues and to design a device that has mechanical integrity and material reliability, an in-depth knowledge of the mechanical behavior of thin film materials is required. This information will help engineers integrate materials and design devices that are mechanically reliable and can perform their specific functions during their life-time without any mechanical failure.

In addition to the tremendous industrial and technological driving force that was mentioned earlier, there is a strong scientific motivation to study the mechanical behavior of thin film materials. The mechanical behavior of thin film structures have been known to drastically differ from their bulk counterparts. (Xiang, 2005) This discrepancy that has been referred to as the length-scale effect has been one of the main motivations in the scientific society to study the mechanical behavior of thin film materials. In order to provide fundamental mechanistic understanding of this class of materials, old problems and many of the known physical laws in materials science and mechanical engineering have to be revisited from a different and multidisciplinary prospective. These investigations will not be possible unless a concrete understanding of the mechanical behavior of thin film materials is achieved through rigorous experimental and theoretical research in this area.

\section{Mechanical testing methods for thin film materials}

In order to probe the mechanical behavior of thin film materials different approaches have been used by researchers. Tensile testing, nano-indentation (Olivier \& Pharr, 2004), bulge test (Vlassak \& Nix, 1992; Xiang et al., 2005), curvature method, micro-beam bending (Freund \& Suresh, 2003), and a few other techniques were used to measure the mechanical properties of thin films on substrate and free-standing thin films. Among these methods, the first four techniques were more popular among the researchers and different measurements have been carried out using these methods.

In tensile testing, the film is patterned into a dog-bone shaped specimen and is then loaded in tension. By monitoring the load and strain across the gage length, the mechanical properties of the film in different load conditions namely monotonic, fatigue, creep, and relaxation can be found. Although tensile testing has been the primary method of experimental research in macro-scale applications, it has not been traditionally as popular among the thin film researchers, due in part to the difficulties in specimen handling, gripping, and strain measurements. However, the tensile testing has a unique advantage that all of the properties of the material can directly be extracted from the measurement data and no calibration model is required. On the other hand and in contrary to other methods, all loading conditions can be applied to the specimen and both free-standing films and films on substrate can be tested using this technique.

In bulge test method, a thin film specimen is loaded by a hydrostatic pressure and the deflection of the specimen is monitored. The pressure-deflection data is then correlated to the actual plain stress-strain behavior of the material through a correlation model. Freestanding single layer and multi-layer materials can be tested by this technique. The only application of this method that is reported in the literature is the monotonic static testing of thin film materials. 
Nano-indentation is the advanced version of the classical hardness test method. In this technique, the specimen is loaded by a sharp indenter and the load-displacement $(P-h)$ of the indenter is monitored during loading and unloading. The reduced elastic modulus and hardness are the two material parameters that can be extracted from the $P-h$ data. This method can only be used for thin films on substrate.

Curvature method is one of the early methods that was used to probe the mechanical behavior of the thin film materials on substrate. In this method, the initial curvature of a substrate is measured and then the film material is deposited on the substrate. The variations in the curvature of the substrate before and after the deposition of the film are a good measure of the residual stresses in the film. This method can also be used to investigate the mechanical behavior of thin film materials on substrate under temperature cycling.

Among the aforementioned experimental methods, tensile testing technique is the only technique that can be used to extract the mechanical behavior of thin film materials under different loading conditions. In this method, all material parameters can be directly measured from the experimental data and it provides a straight-forward approach to the measurement. However, this method faces its own challenges in sample preparation, handling, and gripping and involves uncertainties in the measured strains. In the following sections, these challenges are discussed and different approaches to tackle these problems are presented.

\section{Tensile testing techniques for thin films}

The early efforts in the tensile testing of thin films were the concurrent research work of Ruud et al., 1993, Koskinen et al., 1993, and Read \& Dally, 1993 in the early 1990's. Ruud et al., 1993 introduced a tensile testing technique to test free standing thin film specimens with gage section area of $10 \mathrm{~mm}$ long by $3.3 \mathrm{~mm}$ wide. They sandwiched the specimen ends between polished aluminum grippers using $5 \mu \mathrm{m}$ thick copper films and used a motordriven micrometer for loading. Strain was measured by monitoring the displacement of laser spots diffracted from a series of lithography patterned photoresist islands. With this technique, they managed to determine the Young's modulus, Poisson's ratio, and yield strength of free-standing $\mathrm{Cu}, \mathrm{Ag}$, and $\mathrm{Ni}$ films (Ruud et al., 1993) and $\mathrm{Ag} / \mathrm{Cu}$ multilayers (Huang \& Spaepen, 2000), and to study the yield strength (Yu \& Spaepen, 2004) and anelastic behavior (Yu, 2003) of thin $\mathrm{Cu}$ films on Kapton substrate.

Koskinen et al., 1993 used a relatively simple technique to test LPCVD polysilicon films. They introduced a gripping setup that could hold an array of 20 samples and was capable of loading individual specimens. Specimen ends were glued to the gripper and loaded by a motor driven stage. Gripper displacement was measured and used to calculate the strain.

While both of these techniques suffered from a reliable gripping and load train alignment, Read \& Dally, 1993 and Read, 1998a, 1998b developed a sample fabrication procedure that could meet the demanding gripping and alignment issues, simultaneously. In their method, films were deposited on silicon substrate and after patterning the film to a dog-bone shape, the substrate was etched from the backside to open a window frame under the film, leaving it free-standing. After mounting the specimen in grippers, the frame edges were cut so that only the film is carrying the load. In this way, since the thick substrate is mounted in gripper jaws, there would be less slip and alignment will be an easier task. The concept of free standing film on supporting frame was used by other researchers to overcome the 
alignment issues (Cornella, 1999; Sharp et al., 1997; Emry \& Pvirk, 2004a,2004b). This setup was later on improved by adding laser speckle interferometry (Read, 1998) and Digital Image Correlation (DIC) (Cheng et al., 2005) to measure in-plane strains. E-beam evaporated Ti-Al-Ti multilayer (Read \& Dally, 1993), polySi, aluminum and its alloys, and electrodeposited copper (Cheng et al., 2005) were tested using this technique in the temperature range of $25-200^{\circ} \mathrm{C}$.

William Sharpe (Sharpe et al., 1997; Yuan \& Sharpe, 1997; Sharpe et al., 2004; Edwards et al., 2004; Oh \& Sharpe, 2004) used interferometric strain displacement gage (ISDG) technique to measure strains in free-standing films under tensile loading. The ISDG was originally developed in the late 1980's for strain measurement in a non-contact mode (Sharpe, 1968, 1982, 1989) and macro-scale high-temperature applications (Li \& Sharpe, 1996). This technique is based on Young's two-slit interference (Born \& Wolf, 1983) generated from the diffraction of a laser beam from two sufficiently separate markers. Tensile behavior of polysilicon (Sharpe et al., 1997) and silicon nitride (Edwards et al., 2004) were studied using this technique. Oh \& Sharpe, 2004 used this technique to investigate thermal expansion and creep behavior of polysilicon films, while Zupan (Zupan \& Hemker, 2002; Zupan et al., 2001) studied the high temperature properties of $\gamma$-TiAl micro samples.

The tensile behavior of free standing gold films was studied by Emery and Povirk, 2003a, 2003b. They used the procedure of Read \& Dally, 1993 for sample preparation and measured the cross-head displacement for strain calculations. Bravman group (Cornella, 1999; Lee et al., 2000) used the same concept to study the mechanical behavior of thin films with an emphasis on time dependent behavior of Al films. (Zhang et al., 2001; Lee et al., 2000, 2003, 2004, 2005)

Allameh et al., 2003, 2004 investigated fatigue behavior of LIGA Ni thin films under tensile loading. They used Focused Ion Beam (FIB) to mill $1 \mu \mathrm{m}$ deep markers on the specimen surface and monitored the motion of these markers under an optical microscope to calculate strain. Since LIGA films are relatively thick, i.e. a few tens of micrometers, they used common mounting methods for specimen gripping.

The advent and wide-spread availability of high resolution microscopy techniques led some researchers to use in situ tensile testing methods to characterize the mechanical behavior of thin films. Atomic Force Microscopy (AFM), Transmission Electron Microscopy (TEM), and Scanning Electron Microscopy (SEM) were among the instruments that were used for in situ studies. These techniques were utilized either to measure strain or to study the microstructural deformations during specimen loading. Chasiotis and Knauss (Chasiotis \& Knauss, 2002; Chasiotis, 2004; Knauss, et al., 2003) used AFM to measure the changes in surface topography during the loading and correlated this measurement to strain field using Digital Image Correlation (DIC). They also revised the electrostatic gripping technique, originally proposed by Tsuchiya et al., 1997, 1998, to prevent specimen slipping during the long-time AFM scans for each measurement point. They used this technique to study the influence of surface conditions (Chasiotis \& Knauss, 2003a) and the size effect of elliptical and circular perforations (Chasiotis \& Knauss, 2003b) on the mechanical strength of polysilicon. Chasiotis et al., 2007 used the same setup to study the strain rate effect on the mechanical behavior of $\mathrm{Au}$ films. However, due in part to the slow scan rate of AFM, they used cross-head displacement for strain measurements. Zhu et al., 2003 integrated the specimen with the loading system in a MEMS based device and used AFM to measure strains in polysilicon films under uniaxial tensile loading. 
Haque \& Saif, 2003, 2004 proposed a quantitative technique to study the deformation mechanisms in $\mathrm{Al}$ and $\mathrm{Au}$ nano-scale thin films. They used a MEMS device to load samples in TEM and SEM. Using the same technique, Samuel \& Haque, 2006 studied the relaxation of Au films and Rajagopalan et al., 2007 reported the plastic deformation recovery in $\mathrm{Al}$ and Au thin films.

The above-mentioned methods were among the main research activities that used tensile testing to study the mechanical characteristics of thin film materials. In the following sections, the different parts of the current tensile testing devices, including gripper, loading system, and strain measurement subsystem along with the sample preparation process is discussed in more details. Future researchers can use the information provided in the following sections to choose appropriate solutions to their specific requirements in tensile testing of thin film materials.

\section{Sample preparation and microfabrication techniques}

Sample preparation is one of the main challenges in tensile testing of thin film specimens. Thin film materials are usually fabricated using one of the deposition techniques. In order to utilize any of these techniques to fabricate free-standing thin film "dog-bone" specimens, a designated microfabrication process has to be developed. This process depends on the specific requirements defined by the choice of gripping and sample handling method, the film material and deposition technique, and the availability of the specific procedures in any fabrication laboratory.

Ruud et al., 1993 used a relatively simple technique to fabricate free-standing films. They evaporated $\mathrm{Cu}$ and $\mathrm{Ag}$ films on glass substrate and after patterning the film to a dog-bone shaped specimen, they took the films off the substrate by sliding a razor blade underneath them while submerged in water. For Ni films, glass substrate was first coated with a layer of photoresist and $\mathrm{Ni}$ was then sputter deposited on it. The film was then released by etching the resist in acetone. Although both processes developed by them are relatively simple, films are prone to be damaged and wrinkle while releasing.

The concept of using a window frame in the substrate which was originally introduced by Read \& Dally, 1993 was among the most popular methods that was used and further developed by other researchers. In this process, double-sided polished (DSP) <100> silicon wafers, were first coated by a thin layer of silicon oxide. Oxide layer on front-side was patterned and etched at specimen locations. Thin film material of interest was then deposited by e-beam evaporation and patterned to dog-bone shape specimens. The oxide layer on both sides was then patterned and etched in HF to form a hard mask for silicon substrate etching. Silicon was then etched in hydrazine to open window frames. Sharpe et al., 2003 utilized this technique to test thin polysilicon films. Figure 1-a shows a silicon carbide specimen that was fabricated by Edwards et al., 2004 using this concept. Emery \& Povirk, 2003a, 2003b used the same process to fabricate e-beam evaporated gold. The main issue with this technique is the long $\mathrm{Si}$ substrate etching times that may cause the specimen film be attacked during etching process and special care is required in this regard.

Cornella, 1999 improved this concept by using dry etching processes rather than wet etching processes to fabricate specimens with higher film quality and process yield. In their process, Si substrate was first coated on front side with $1 \mu \mathrm{m}$ thick LPCVD silicon nitride to be used as an etch stop. Aluminum was then sputter deposited on front side and patterned to the dog-bone shape. Backside of the substrate was coated with thick photoresist to act as the 
etching mask during substrate etching. Silicon substrate was entirely dry-etched until it reached silicon nitride layer. This layer was then removed in RIE to release the aluminum specimen. The specimen fabricated through this process is shown in Figure 1-b.

(a)

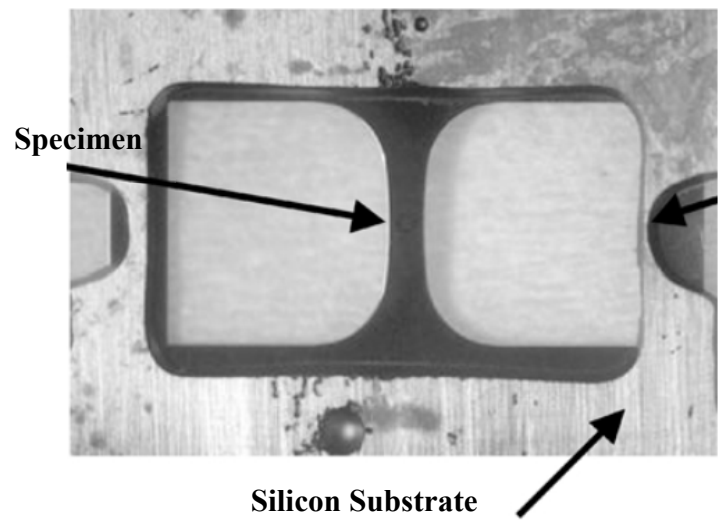

(b)

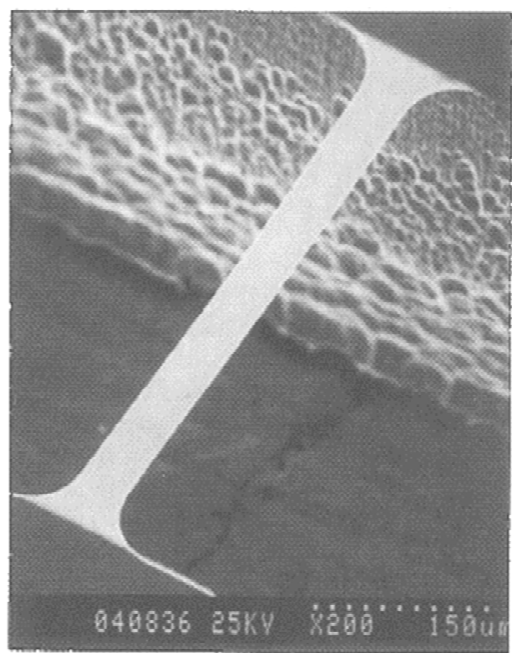

Fig. 1. (a) A free-standing silicon carbide specimen on substrate window frame (Sharpe et al., 2003) and (b) SEM image of an Al free-standing film on window frame. (Zhang et al., 2001)

A few researchers, who mainly worked on the mechanical behavior of polysilicon, used factory processes like polyMUMPS to fabricate their specimens. The specimen is then released by etching the oxide sacrificial layer. Although these processes are well developed and are readily available, they are limited to a few thin film materials, most of which are silicon based. When metallic materials are used as the structural layer, traditional siliconbased films are not good choices for sacrificial layer. A common practice in the fabrication of free-standing metallic devices in RF MEMS devices is to use polymers as the sacrificial layer. Chasiotis et al., 2007 used this technique to fabricate tensile specimens of Au films. As shown in Figure 2, they used PMMA and AZ 4110 photoresist as the sacrificial material for electroplated and evaporated Au films, respectively. For electroplated Au films, a molding process was utilized to pattern gold on PMMA and sacrificial layer was then etched to release the film. Evaporated Au films, however, were lithography patterned and the photoresist sacrificial layer was then stripped to release the structure. Although polymeric sacrificial layers are easier to remove and hence result in less attack to the metallic film, they are less applicable when high temperature processes are involved. In fact in high temperatures two problems arise; above the glass transition temperature, polymer layer starts a significant flow which causes deformation and wrinkling in the metallic film; on the other hand, the thermal mismatch between the polymer and the metallic film causes significant stresses on the film that, in high temperatures, may result in creep and permanent deformation. (Stance et al., 2007) Tajik, 2008 optimized this process in order to realize free-standing thin film specimens that are free of wrinkle and warpage. 
A

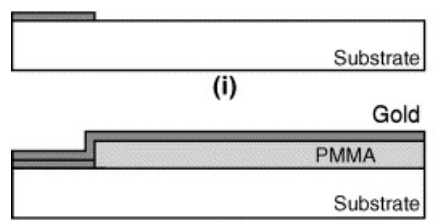

(ii)

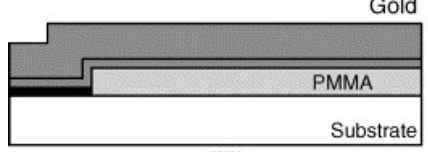

(iii)

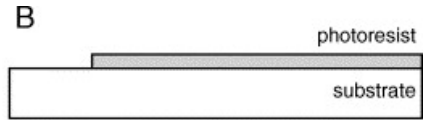

(i)

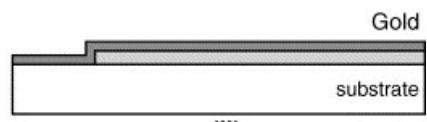

(ii)

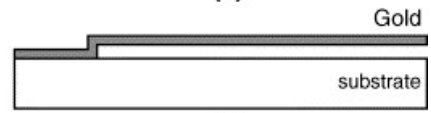

(iii)

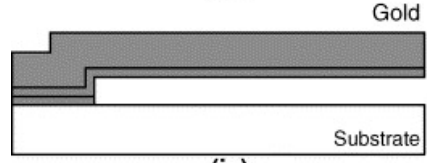

(iv)

Fig. 2. Microfabrication process for electroplated (A), and evaporated (B) dog-bone specimens. (Chasiotis et al., 2007) In brief, for electroplated specimens (A), Ti/ Au anchor is deposited via lift-off process (i), PMMA is spun coated and patterned through photolithography and RIE etching, and then, a thin Ti/Au seed layer is evaporated and patterned to the dog bone shape specimen (ii), a thick Au layer is deposited via electroplating to realize the final dog bone specimen (iii), PMMA sacrificial layer is etched to release the structure (iv). In the case of evaporated films (B), photoresists is used as the sacrificial layer and patterned via photolithography (i), Au film is evaporated and patterned (ii), and the sacrificial layer is then removed in stripper (iii).

\section{Gripping}

Gripping a film that usually has smaller thickness than even the surface roughness of the macro-machined grippers is a tough challenge. Under these circumstances, the film may slip or experience high stresses at the gripping location due to stress concentrations. On the other hand, aligning the two grippers is, in fact, a demanding task. Therefore, many researchers have designed and utilized a variety of gripping techniques to overcome this issue.

Ruud et al., 1993 sandwiched the free-standing thin film specimens between polished aluminum grippers using $5 \mu \mathrm{m}$ thick $\mathrm{Cu}$ foils. The concept of window frame in substrate (Read \& Dally, 1993; Cornella, 1999) has made gripping much easier and common macromachined grippers can be used to mount thick end grips of the specimen which is basically the thick silicon substrate rather than the thin film. As shown in Figure 3, Greek \& Johnson, 1997 and Greek et al., 1997 used a connecting ring as a gripper. They inserted a probe connected to the load-train setup in the ring and loaded the specimen. Buchheit et al., 2003 used the same concept to pull micromachined silicon films. A cylindrical sapphire nanoindenter tip was inserted into the so-called "pull-tab" and utilizing the lateral loading capability of a nano-indenter, samples were loaded in tension. Emry \& Povirk, 2003a, 2003b used the same technique for pulling tensile specimens on a substrate window frame. This 
methods, however, is only useful when tension-tension loading scenario is used. In cases where loading direction is changed or set to zero, backlash and rigid displacements cannot be avoided.

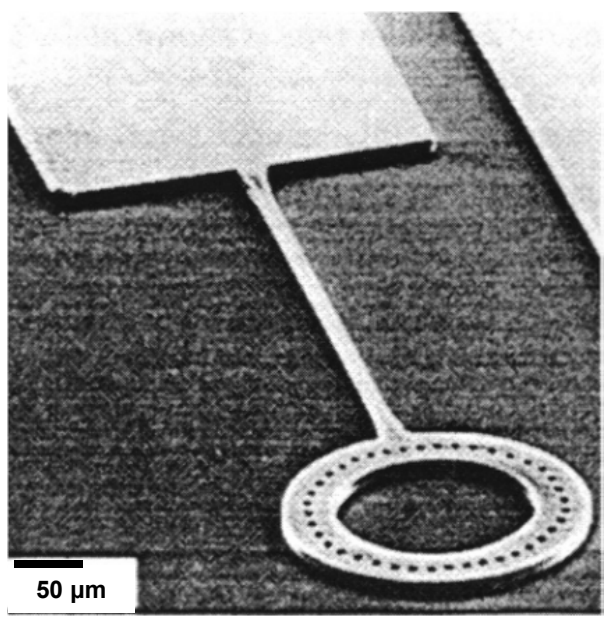

Fig. 3. Tensile testing specimen with a ring at one end for gripping and loading (Greek \& Johnson, 1997)

Tsuchiya et al., 1997, 1998 introduced a novel technique to grip tensile testing specimens using electrostatic force. This technique is schematically shown in Figure 4-a. In this technique, a free-standing specimen with large end grip (puddle) is fabricated and is fixed to the gripper by electrostatic force. Specimen can be easily fixed to and released from the gripper by changing the polarity of the applied voltage. Sharpe \& Bagdahn, 2004 argued that although the electrostatic gripping is very useful in static tensile tests, it fails during tension-tension fatigue testing. To overcome this issue, they glued a silicon carbide fiber to the puddle using viscous UV curable adhesive.

Chasiotis \& Knauss, 2002 also reported that specimens mounted by electrostatic gripping slip during long-time static loadings and they experienced rigid-body motion of the specimen during their long-time AFM scans for deformation measurement. It was shown that the electrostatic gripping is only reliable when the applied tensile loads are below $0.1 \mathrm{~N}$ for their specimen geometry. They improved the technique by combining the electrostatic actuation with UV adhesive to meet their demanding requirements for a no-slip reliable gripper. (Figure 4-b)

In order to avoid slipping of the film at the gripper, Tajik, 2008 used a novel gripping method that could reliably grip the specimen for different modes of loading. In this method, the conventional serrated jaw macro-machined gripper was mounted on a double action arm. This mechanism provides a tight gripping of thin film micro-specimens, though the gripper itself is of macro-scale size. (Figure 5)

In conclusion, the application of substrate frame window concept makes griping much easier in the expense of having a more complicated specimen fabrication process. The 
electrostatic gripping, although seems straight forward, is only applicable for static low-load $(<0.1 \mathrm{~N})$ tests. The utilization of adhesive layer is necessary when conducting timedependent tests or applying a dynamic load that requires a reliable no-slip gripper.

(a)
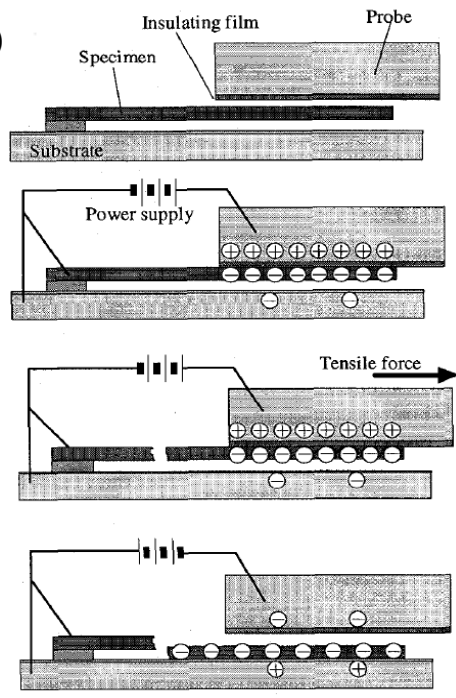

(b)

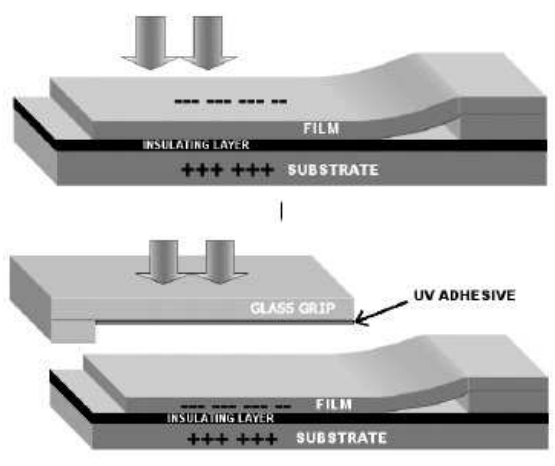

II

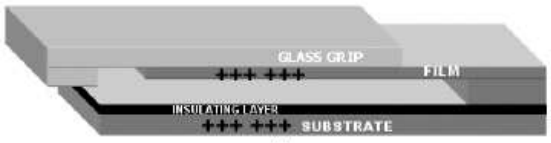

III

Fig. 4. (a) Schematic representation of electrostatic gripping technique (Tsuchiya et al., 1997) and (b) Combination of the electrostatic and UV adhesive gripping. (Chasiotis \& Knauss, 2002)
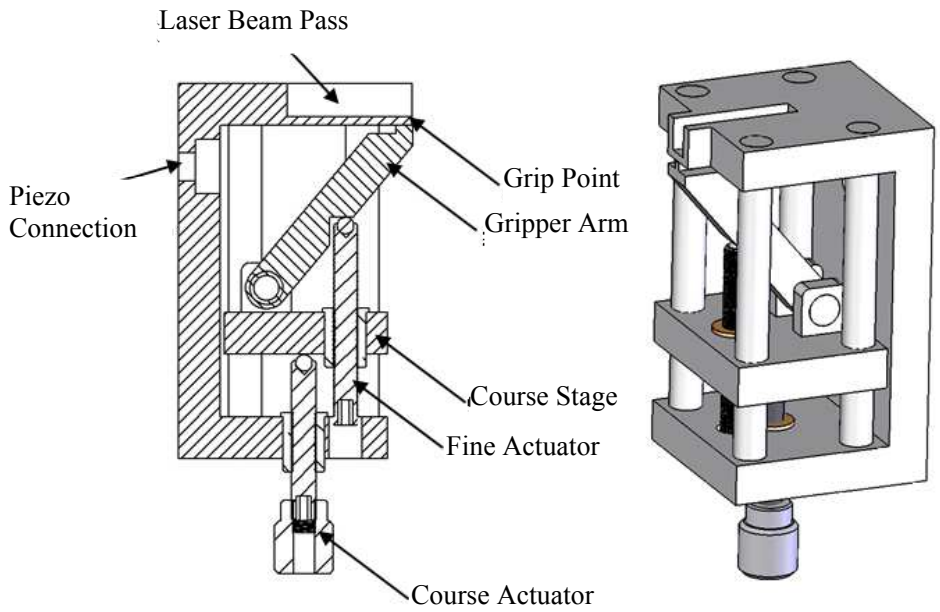

Fig. 5. The double action gripper (Tajik, 2008) 


\section{Load actuation and measurement}

Having prepared the samples and mounted them in grippers, they had to be loaded to the required load level and the load value has to be measured. With the availability of different types of commercial actuators and load cells, this part of a tensile testing setup is not as challenging as the other parts. Piezo driven actuators were among the popular tools for loading. These actuators provide the capability of loading the specimen with different waveforms and frequencies. If they are fitted with any type of displacement sensor, e.g. strain gage, LVDT, or capacitive sensors, they can be controlled in a close-loop system in order to compensate for hysteresis and drift. On the other hand, this displacement feedback can be recorded as the cross-head displacement and be used for the measurement of strain. Many of the research works discussed earlier in this chapter are equipped with this type of actuators (Read \& Dally, 1993; Cornella, 1999; Sharpe et al., 1997; Zupan \& Hemker, 2001; Allameh et al., 2004). Inchworm (Chasiotis \& Knauss, 2002) and motor-driven micrometer (Ruud et al., 1993) actuators are also among the type of actuators that were used for specimen loading. Sharpe \& Bagdahn, 2004 used a loud-speaker operating at $20 \mathrm{kHz}$ in their early fatigue tests on polysilicon to dynamically load their specimens at high frequencies. Almost all research groups used strain gage-based load cells to measure the applied load and hence the stress. Tajik, 2008 also used piezoelectric actuators along with precision strain gage load cells that can provide static and dynamic loading capabilities to test thin film specimens as thin as $300 \mathrm{~nm}$.

A specific group of tensile test setups are those that have integrated the load-actuation and measurement with the specimen itself on a MEMS-based tensile testing device. These devices provide much higher resolution for load actuation and load measurement, making them a versatile tool to study the mechanical properties of nano-scale structures like carbon nanotubes and nano-wires (Zhu et al., 2007), and films that are substantially thin or have very small gage section areas. (Haque \& Saif, 2004) On the other hand, because of their small size, they can be used for in situ study of deformation in Scanning Electron Microscope (SEM) or Transmission Electron Microscope (TEM). (Zhu et al., 2003; Haque \& Saif, 2003, 2004; Samuel \& Haque, 2006; Rajagopalan et al., 2007) However, these devices are not so applicable at the length scale where most of the thin films are usually fabricated and used in MEMS and microelectronics applications.

\section{Strain measurement}

The measurement of strain is the most challenging part of the tensile testing of thin film specimens. Due to the small size of thin films, none of the current macro-scale methods of strain measurement are applicable to tensile testing of thin films. Thin film specimens are at the same size scale of resistive strain gages and are too small for LVDT-based extensometers. Technically, any method of strain measurement that is used in contact with the specimen is not useful. Therefore, many researchers have developed or adapted non-contact strain measurement techniques to measure the strain during tensile testing. These techniques can be categorized into four different groups, including cross-head displacement; optical imaging; interferometry-based methods; and advanced microscopy techniques like AFM, SEM, and TEM for in situ strain measurement. In what follows, these methods are discussed in detail. 
Read \& Dally, 1993 monitored the cross-head displacement and used it as a measure for strain. There are many sources of error involved in this technique. Specimen may slip at the gripper. On the other hand, the gripper itself may have clearances that cause backlash during the changes in load direction. Compliance of the test setup is the other source that deteriorates the accuracy of the method. The cross-head displacement is a combination of all of the deformations in the load train, i.e. the deformations in load-cell, load actuator, the test rig, grippers and albeit in the specimen itself. Therefore, this measurement will not provide an accurate measure of stain in the gage section of the sample.

Cornella, 1999 measured the compliance of the test setup by compressing the load actuator to the load cell in the absence of specimen and subtracted this compliance from the actual measurements to find the deformation in the specimen. They reported that $76 \%$ of the measured displacement accounts for the actual deformation in the specimen (Zhang et al., 2006). In order to validate the strain relaxation measurements and to show that the drop in the stress level over time is the actual behavior of the specimen itself and not the test setup, they used iridium specimens. Iridium, due to its high melting point, has a very low relaxation at room temperature. Since these tests revealed no relaxation, they argued that their test setup is stiff enough and that the relaxation behavior that they monitored during the tensile testing of $\mathrm{Al}$ films is the actual material behavior.

Chasiotis et al., 2007 used the cross-head displacement to study the relaxation in gold thin films. They measured the deformation of the load-cell and the apparatus compliance and subtract it from the results. Due to the high compliance of their specimens compared to the setup, $99 \%$ of the cross-head displacement was due to the deformation in the specimen. They verified the accuracy of the crosshead displacement method by testing brittle materials with known elastic modulus.

Greek \& Johnson, 1997 cancelled out the effect of the compliance of the test setup by testing specimens with identical gages section areas and different gage lengths. Assuming that the compliance of the test setup is constant for any test, they calculated the deformations caused by test setup and subtract it from the test results. This method is only applicable to the cases that the compliance of the specimens are sufficiently different at different gage lengths.

Emry \& Povirk, 2003a also measured the displacement in grippers by monitoring the displacement of two markers using a video camera. They argued that their method has the limitation that the measured strain is not the actual strain in the gage section. They also reported a non-linearity in the stress-strain curve in low loads. Figure 6 shows this nonlinearity which is technically an experimental error. They extrapolated the linear portion of the results to find the zero point of stress-strain curve. Due to this non-linearity in the curve, calculating the yield stress using the $0.2 \%$ offset rule was erroneous. Therefore they found the yield point by defining it as the point where the slope of the stress-strain curve drops to one tenth of the elastic modulus.

Due to the uncertainties involved in the application of cross-head displacement for strain measurements, a number of techniques have been introduced to measure the strain directly on the gage section. An inexpensive way of measuring strain is to put markers on the specimen's gage section and monitor their displacement using a camera. Allameh et al., 2004 used a video camera and monitored the deformation of two markers milled by Focused Ion

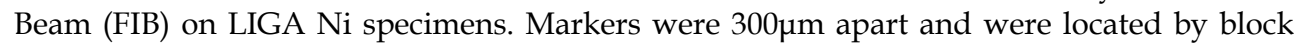
matching in a series of images captured by a camera during tensile testing. They have not 
discussed the accuracy of their setup; however, they reported that the strains that were measured as such were only used in the plastic deformation regime. In this method, one way to achieve higher displacement measurement resolution is to use higher optical magnification. However, at high magnifications, the field of view (FOV) of the objective is so small that the two markers cannot be fit in a single image, simultaneously. To overcome this issue, two different approaches have been used. Cheng et al., 2005 used a low magnification $(350 \mathrm{X})$ to fit $180 \mu \mathrm{m}$-apart markers in a single image. Utilizing the digital image correlation (DIC) method, they post-processed the data to the resolution of 0.02 pixel. For their optical setup, this resolution is the equivalent of $0.01 \mu \mathrm{m}$ displacement on the specimen which translates to $55 \mu$ strain resolution for a $180 \mu \mathrm{m}$ gage length. Since compared to other techniques, usually less or no preparation is required on the surface of the specimen and inexpensive optical imaging equipment can be used for this purpose, this method is becoming more popular among researchers. The only disadvantage of DIC is that this method is computationally expensive and therefore cannot be used in real-time and straincontrolled measurements.

In another attempt to tackle the small FOV issue in high magnifications, Ogawa et al., 1997 proposed a double field of view approach. As shown in Figure 7, a low magnification objective is used to view the two markers which were 1-1.4mm apart. Image of each marker position was then magnified on a separate CCD and their displacement was monitored. In their technique, they could measure displacements to better than $1 \mu \mathrm{m}$ corresponding to $0.1 \%$ strain for a $1 \mathrm{~mm}$ gage length.

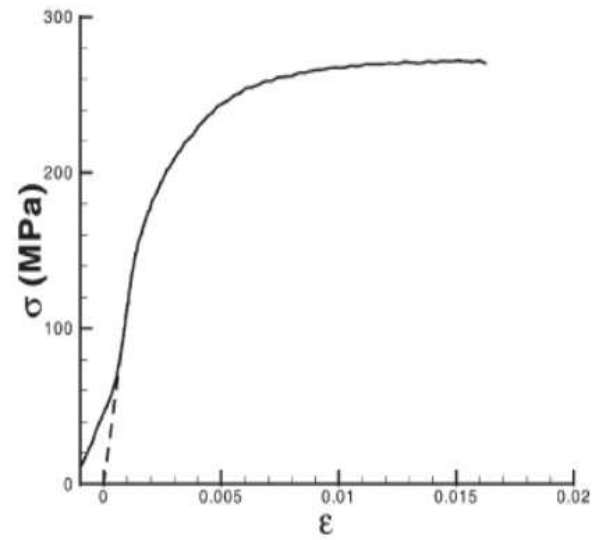

Fig. 6. Stress-strain curve of gold thin films, showing non-linearity at low loads. The dashed line is fitted to the curve to find the zero point. (Emry \& Povirk, 2003a)

Ruud et al., 1993 patterned a two-dimensional area of photoresist islands on the specimen and monitored the displacement of the diffracted spots from these islands to directly measure the strain on the gage section. As shown in Figure 8, presence of the photoresist islands results in diffraction patterns when a laser beam is illuminated on the surface of the sample. Diffracted spots are then detected using a two-dimensional position sensor. By monitoring the displacement of these spots, the relative displacement of the islands and hence the specimen deformation can be measured. In this setup, system works in the third diffraction order and the distance between the sample and position detector serves as an 
optical lever for magnification. They reported that the resolution of the system is limited by the signal-to-noise ratio of the detector and provides strain resolution of 50 $\mu$ strains.

The main advantage of this technique is that since axial and lateral strains can be measured simultaneously, not only Young's modulus but also the Poisson's ratio can be calculated. Since the modulus of the photoresist islands is sufficiently lower than that of the film's, their presence has very negligible effect on the mechanical behavior of the specimen material.

The aforementioned techniques were all based on optical imaging. The main issue with imaging techniques is that their resolution is limited by the optical setup, and more specifically by the magnification and the CCD resolution. An advanced method of improving the resolution of optical devices is to use light interference. This approach which is the basis of interferometry techniques has been used by a few researchers for strain measurement in thin film materials.

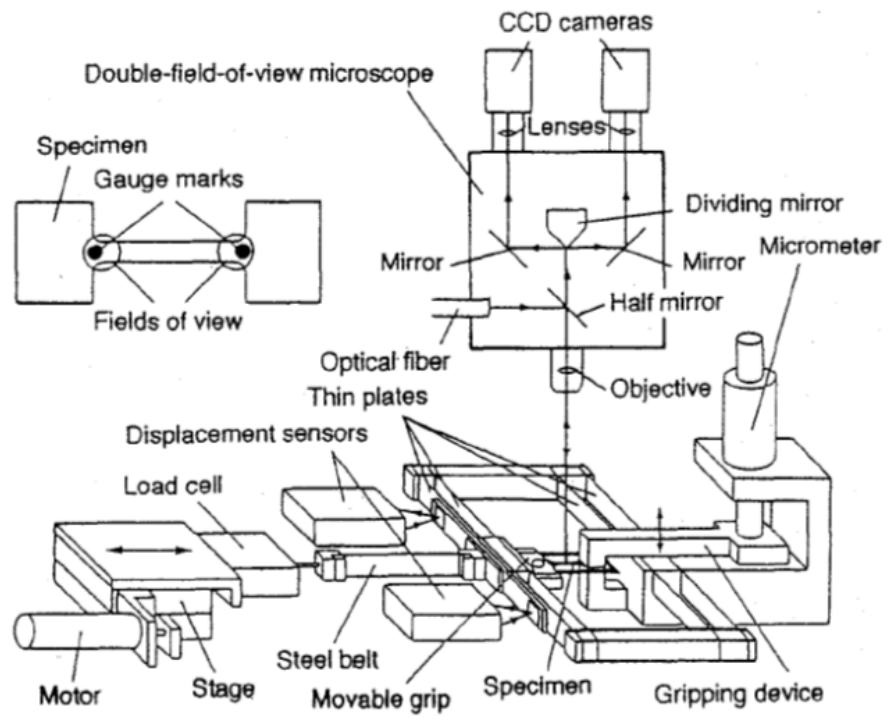

Fig. 7. Double field of view microscope setup for strain measurement (Ogawa et al., 1997)

Sharpe et al., 1997 used Interferometric Strain/Displacement Gage (ISDG) method to measure axial and lateral strains in thin film specimens. ISDG was originally proposed by Sharpe (Sharpe, 1968, 1982, 1986, 1989) in the late 1980s to measure strains in macrospecimens in non-contact mode. The principle of this technique is based on the diffraction and interference of light from two slits, i.e. Young's two slit interference. In this method, two markers are put on the specimen. They can be fabricated either by nano-indentation or by FIB-assisted deposition. When the laser beam is illuminated on them the beam is diffracted. The diffracted beams interfere to form interference fringes. The frequency of the fringes is directly proportional to the distance between the two markers. When the specimen is elongated under the applied load, the distance between the two markers varies, resulting in a change in the fringe frequency. By monitoring this frequency the strains can be directly calculated on the specimen. Since the fringe frequency is also affected by the rigid-body motion of the specimen, two separate detectors have to be used to cancel out the effect of 
this motion. A schematic of this setup is shown in Figure 9. In the original setup, in order to measure the strains from the fringe data, the location of the fringe minimum was isolated at the beginning of the test and was followed through a complex algorithm. In this algorithm only a small part of the optical signal was used and most of it which contained a lot of information was omitted in calculations. With this algorithm, the strain resolution was $5 \mu$ stains with uncertainty of $\pm 30 \mu$ strains. Zupan \& Hemker, 2002 used Fourier Transforms on the whole optical signal and improved the uncertainty of the technique to $\pm 15 \mu$ strains. An advantage of ISDG is that if markers are placed along the width of the specimen, the lateral strains and hence the Poisson's ratio can also be measured with this technique.

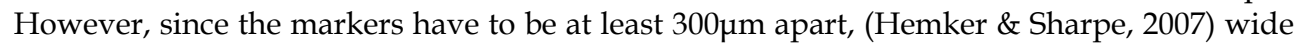
specimens have to be utilized.

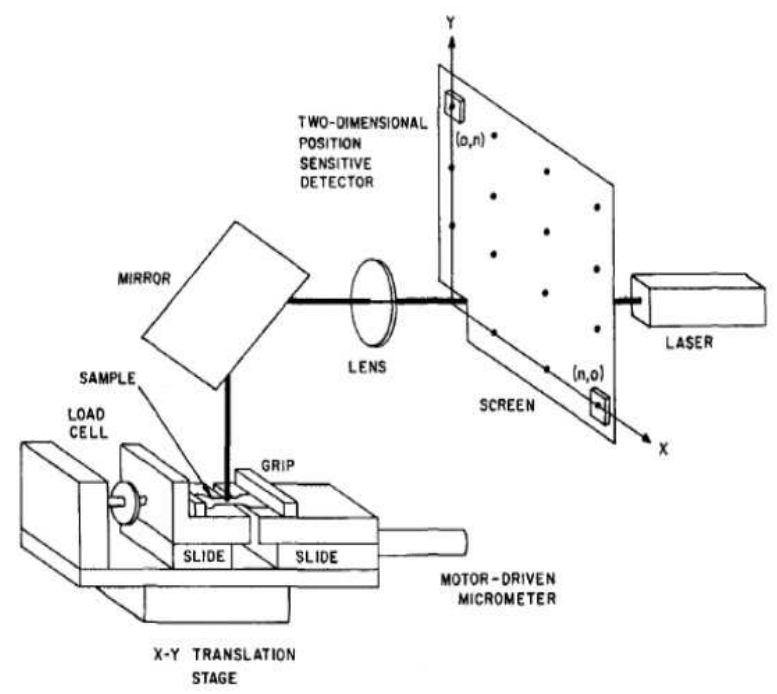

Fig. 8. Schematic diagram of the setup to use diffraction spots for strain measurement (Ruud et al., 1993)

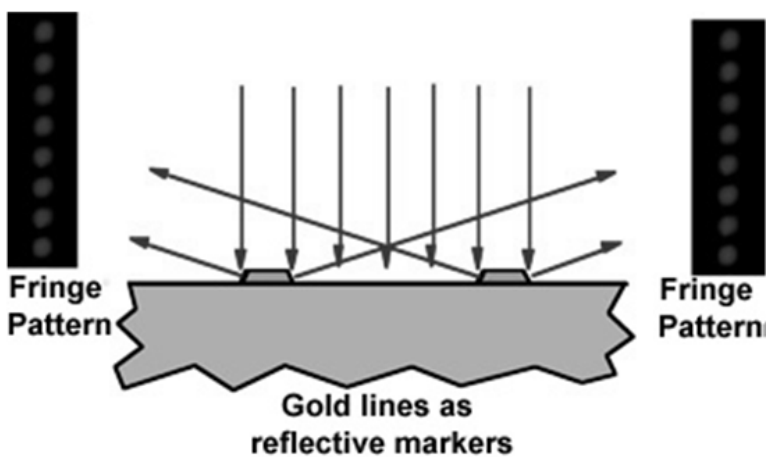

Fig. 9. Schematic representation of ISDG technique. (Sharpe et al., 1997) 
In another effort to use interferometric measurement techniques, Read, 1998 used speckle interferometry to measure in-plane strains in thin film specimens. The main advantage of speckle interferometry is that since it uses the speckles caused by the surface topography, no surface preparation or marker fabrication is required. However, it is usually computationally expensive and has low signal-to-noise ratio. In this technique, instead of the strain, the strain rate was measured in the elastic deformation regime and was used to calculate the modulus of elasticity. The uncertainty of the calculated modulus was reported to be $5 \%$.

Tajik, 2008 used another interferometric technique to measure the strain fields in a thin film specimen. This method is schematically represented in Figure 10-a. Diffraction gratings are milled on the freestanding thin film specimen using Focused Ion Beam (FIB). (Figure 10-b and c) Gratings are then illuminated by two laser beams and the interferogram thus formed is captured via a CCD camera. Deformation of the specimen and hence the gratings will result in changes in the interferogram. Intensity of the interferogram can be correlated to the displacement field, such that

$$
I(x, y)=I_{0}(x, y)+\gamma(x, y) \cos \left(2 \pi\left(2 f_{s}\right) U(x, y)\right)
$$

where $I(x, y)$ is the interferogram intensity, and $I_{0}(x, y)$ and $\gamma(x, y)$ are the background intensity and fringe visibility, respectively. In this equation, $f_{s}$ is the spatial frequency of the gratings and $U(x, y)$ represents in the axial displacement field.

As shown in Equation (1), displacement field is essentially the phase of the interferogram. Therefore, in order to measure displacement field, one needs to calculate the phase value from the interferogram data. For this purpose, continuous wavelet transformation (CWT) has been used in this study. In brief, it has been shown that the spatial derivative of the displacement field, which in fact corresponds to strains, correlates with the value of the scaling parameter at the ridge of the transformation,

$$
\varepsilon_{x x}(x)=\frac{1}{2 f_{s}} \frac{f_{c}}{a_{r}(x)}
$$

where $a_{r}(x)$ is the scale value on the ridge of the wavelet for any coordinate $x$ and $f_{c}$ is the center frequency of the Morlet wavelet. This method is then used to extract uniform and non-uniform strain fields. It is shown that wavelet transformations have exceptional capabilities in denoising the experimental interferogram, given appropriate wavelet parameters are chosen in the analysis. Figure 11 demonstrates the capabilities of this method to reconstruct the non-uniform strain field around a hole in a plate under axial tension.

The last group of strain measurement methods are those that used advanced microscopy techniques to measure the strain in thin films. The challenges involved in using optical microscopy led researchers to use other microscopy techniques like AFM, SEM, and TEM to measure the deformation of thin films specimens. These techniques, on the other hand, can provide an insight into the microstructural deformation of thin film materials during loading.

Chasiotis \& Knauss, 2002 monitored the surface topography changes during loading using Atomic Force Microscopy (AFM). Correlating the AFM images of the deformed and undeformed surface using Digital Image Correlation (DIC), they calculated the strain field. 
The process of imaging is very time intensive and usually takes about 10 minutes for each scan and is confined to an area of a few microns long. In addition to the time required for each AFM scan, there is also the post-processing time added for DIC. They reported 400 $\mu$ strains resolution in their strain measurements for a $512 \times 512$ pixel image and $1 / 8$ pixel DIC resolution. However, the main advantage of this technique is that it provides a wholefield strain data which helped the analysis of the strain field around geometry inclusions and notches (Chasiotis \& Knauss, 2003), as well as cracks. (Chasiotis et al., 2006; Cho et al., 2007). A typical displacement field at the vicinity of a crack in polysilicon that has been measured using AFM/DIC is shown in Figure 12.

(a)

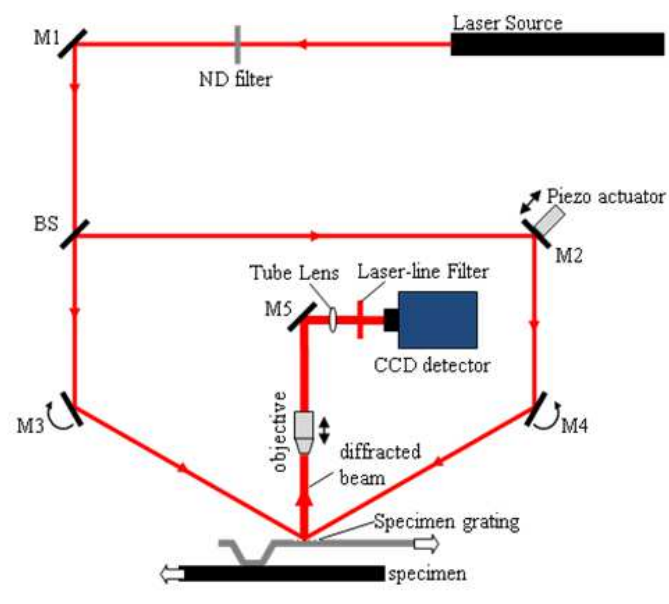

(b)

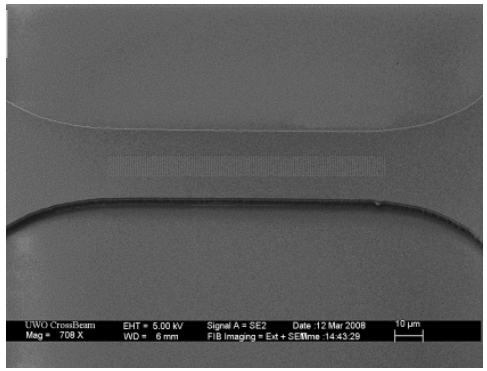

(c)

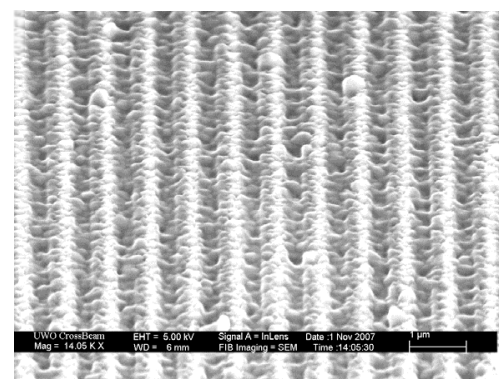

Fig. 10. (a) Schematic representation of the optical setup for moiré interferometry,

(b) diffraction gratings fabricated using FIB milling on the test specimen, and

(c) high magnification image of the gratings on the specimen. (Tajik, 2008)

A few researchers used MEMS based devices to study the mechanical properties of thin films in electron microscopes. If the thin film samples are electron transparent, i.e. have nanometer thickness, in situ studies in TEM are also possible which provides more information on the microstructural deformations during loading. Haque \& Saif, 2003, 2004 used the technique to study the mechanical behavior of $\mathrm{Al}$ and $\mathrm{Au}$ thin film specimens under SEM and TEM. The resolution of the measured strain and stress depends on the magnification of the microscope and the size of the specimen. At 100nm microscope resolution, the strain resolution was $0.05 \%$ for $200 \mathrm{~nm}$ thick and $185 \mu \mathrm{m}$ long $\mathrm{Al}$ films and was $0.03 \%$ for $100 \mathrm{~nm}$ thick and $275 \mu \mathrm{m}$ long specimens. Rajagopalan et al., 2007 reported lower strain resolutions of $0.005 \%$ and $0.01 \%$ for $\mathrm{Al}$ and Au films, respectively. Although this method of strain measurement has a high resolution and provides extra information on the microstructural deformations, its force and displacement scales are within the limits of 
nanostructures rather than common thin film materials. A stress-strain curve along with respective microstructural observations produced by this method is shown in Figure 13.

(a)

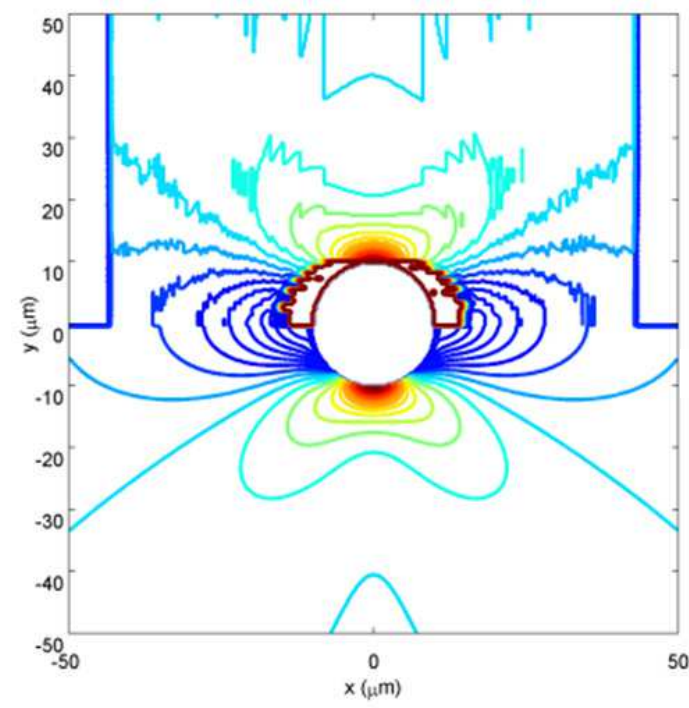

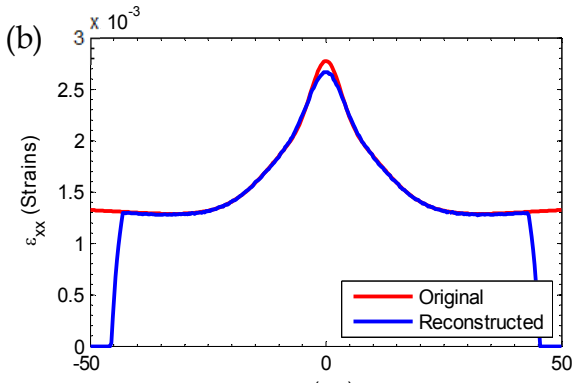

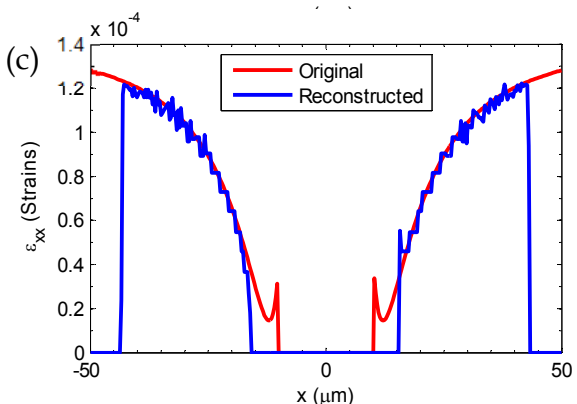

Fig. 11. (a) Reconstructed (top) and original (bottom) strain field using continuous wavelet transformations, $(b)$ reconstructed strains at top of the hole $(y=12 \mu \mathrm{m}),(\mathrm{c})$ through the hole $(y=0)$. (Tajik, 2008)

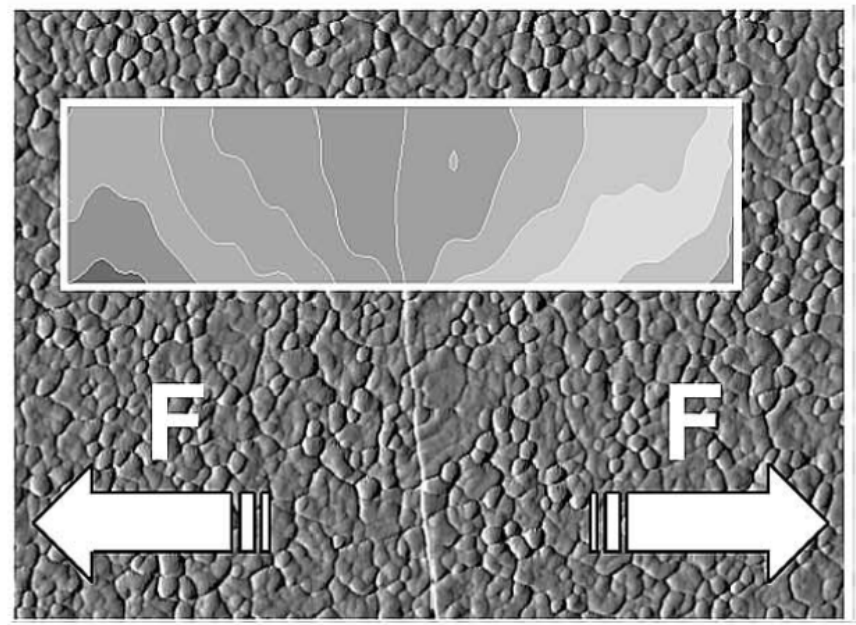

Fig. 12. Displacement field in the vicinity of a crack in polysilicon film measured by AFM/DIC. (Chasiotis, 2004) 


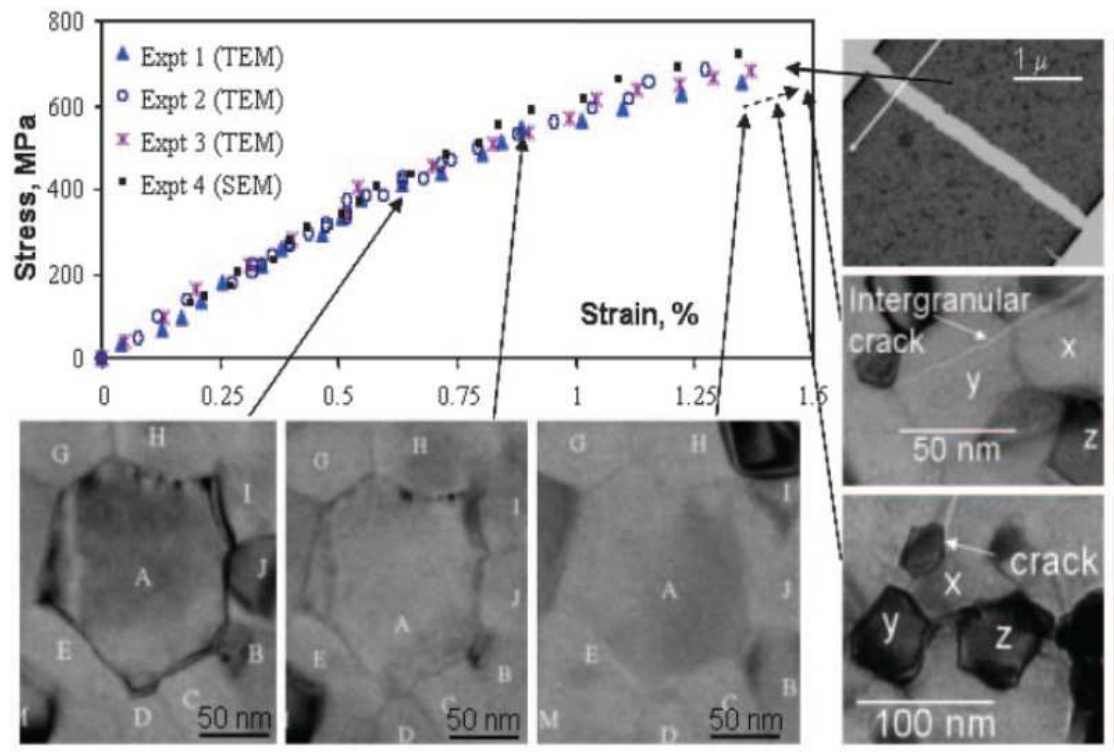

Fig. 13. In situ TEM test results for Al thin film specimens. Microstructural deformations corresponding to the tensile test is also presented. (Haque \& Saif, 2004)

\section{Conclusion}

In this chapter, the major research activities that used a tensile testing method to study the mechanical behavior of thin film materials were reviewed. For this purpose, most of the research groups designed and used their custom made test setups. A historical overview of the development of these test devices is presented. Early research in this filed started in early 90's and has continuously been pursued since then. Tensile testing research is categorized into four major steps, namely sample preparation, gripping, load actuation and measurement, and strain measurement. Each research group has mainly tackled one of these challenges and tried to implement innovative designs to address these requirements. Each one of these steps is discussed in detail in their designated sections 57. Overall, among all the sample preparation techniques reviewed here, the window frame approach and polymeric sacrificial layer seems to be the most reliable fabrication processes. In terms of gripping, depending on the sample geometry, fabrication technique, and loading requirements, any of the methods presented by Tajik, 2008, Cornella, 1999, or Chasiotis \& Knauss, 2002 can be utilized. A combination of window frame specimen and rough macro-gripping seems to be basis of future tensile testing techniques. Piezo actuators can be utilized as the loading actuator. They can provide enough resolution and their maximum load is within the range that is required for tensile loading of thin film specimens. Also, they can provide static and dynamic loads which can be used to test specimens under tensile, fatigue, creep, and relaxation experiments. Strain measurement still seems to be the most challenging part of the tensile testing. Different methods have been traditionally used in these experiments; however, depending on the type of application, each method has its own advantages and disadvantage. Methods based on 
interferometry have much higher resolution and can be used to extract strain values as well as strain fields. However, their main disadvantage is the hardware complexity and cost. On the other hand, optical imaging methods in combination with Digital Image Correlation (DIC) can provide about the same resolution; however, they are computationally expensive and cannot be used in real-time and strain-controlled experiments. Therefore, depending on the specific type of application, one needs to choose either method to measure strains or strain fields across the gage length.

The information obtain through this review provide a detailed understanding of the challenges involved in tensile testing of thin film materials and different approaches that were used to tackled these issues. The results will help design and implement a device that can meet these challenges toward a reliable and precise study of the mechanical behavior of thin film materials.

\section{Acknowledgment}

The financial support from the Natural Sciences and Engineering Council of Canada (NSERC) is appreciated. Center for Integrated RF Engineering (CIRFE) and WatLabs of the University of Waterloo, Nanofabrication Laboratory of the University of Western Ontario and the Canadian Centre for Electron Microscopy in McMaster University are acknowledged for providing research facilities. A great portion of this research is conducted in Laboratory for the Mechanical Properties of Thin Film Materials at the University of Waterloo.

\section{References}

Allameh, S. M. (2003). An introduction to mechanical properties related issues in MEMS structures, Journal of Materials Science, Vol. 38, pp. 4115-4123.

Allameh, S. M., Lou, J., Kavishe, F., Buchheir, T., \& Soboyejo, W. O. (2004). An investigation of fatigue in LIGA Ni MEMS thin films, Materials Science and Engineering A, Vol. 371, pp. 256-266.

Born, M., \& Wolf, E. (1983). Principles of Optics: Electromagnetic Theory of Propagation, Interference, and Diffraction of Light, Cambridge University Press, ISBN 0521642221, Cambridge, UK.

Buchheit, T. E., Glass, S. J., Sullivan, J. R., Mani, S. S., Lavan, D. A., Friedmann, T. a., \& Janek, R., (2003). Micromechanical testing of MEMS materials, Journal of Materials Science, Vol. 38, pp. 4081-4086.

Chassiotis, I., \& Knauss, W. G. (2002). A new microtensile tester for the study of MEMS materials with the aid of Atomic Force Microscopy, Experimental Mechanics, Vol. 42, No. 1, pp. 51-57.

Chasiotis, I., \& Knauss, W. G. (2003a). The mechanical strength of polysilicon films: Part 1. The influence of fabrication governed surface conditions, Journal of the Mechanics and Physics of Solids, Vol. 51, pp. 1533-1550.

Chasiotis, I., \& Knauss, W. G. (2003b). The mechanical strength of polysilicon films: Part 2. Size effects associated with elliptical and circular perforations, Journal of the Mechanics and Physics of Solids, Vol. 51, pp. 1551-1572. 
Chasiotis, I. (2004). Mechanics of thin films and microdevices, IEEE Transactions on Device and Materials Reliability, Vol. 4, No. 2, pp. 176-188.

Chasiotis, I., Cho, S. W., \& Jonnalagadda, K. (2006). Fracture toughness and subcritical crack growth in polycrystalline silicon, Journal of Applied Mechanics, Vol. 73, No. 5, pp. 714-722.

Chasiotis, I., Bateson, C., Timpano, K., McCarty, A. S., Barker, N. S., \& Stanec, J. R. (2007). Strain rate effects on the mechanical behavior of nanocrystalline Au films, Thin Solid Films, Vol. 515, No. 6, pp. 3183-3189.

Cheng, Y. W., Read, T. D., McCloskey, J. D., \& Wright, J. E. (2005). A tensile-testing technique for micrometer-sized free-standing thin films, Thin Solid Films, Vol. 484, pp. 426-432.

Cho, S. W., Jonnalagadda, K., \& Chasiotis, I. (2007). Mode I and mixed mode fracture of polysilicon for MEMS, Fatigue and Fracture of Engineering Materials and Structures, Vol. 30, No. 1, pp. 21-31.

Cornella, G. (1999). Monotonic and cyclic testing of thin film materials for MEMS applications, PhD Dissertation, Stanford University.

Eberl, C., Spolenak, R., Arzt, E., Kubat, F., Leidl, A., Ruile, W., \& Kraft, O. (2006). Ultra highcycle fatigue in pure Al films and line structures, Materials Science and Engineering A, Vol. 421, pp. 68-76.

Edwards, R. L., Coles, G., \& Sharpe, W. N. (2004). Comparison of tensile and buldge tests for thin film silicon nitride, Experimental Mechanics, Vol. 44, No. 1, pp. 49-54.

Emry, R. D., \& Povirk, G. L. (2003a). Tensile behavior of free-standing gold films. Part I. Coarse grained films, Acta Materialia, Vol. 51, pp.2067-2078.

Emry, R. D., \& Povirk, G. L. (2003b). Tensile behavior of free-standing gold films. Part II. Fine grained films, Acta Materialia, Vol. 51, pp.2079-2087.

Freund, L. B., \& Suresh, S. (2003). Thin Film Materials, Stress, Defect Formation and Surface Evolution, Cambridge University Press, ISBN 0521822815 Cambridge, UK.

Gall, K., West, N., Spark, K., Dunn, M. L., \& Finch, D. S. (2004). Creep of thin film Au on biomaterial Au/Si microcantilevers, Acta Materialia, Vol. 52, pp. 2133-2146.

Greek, S., \& Johnson, S. (1997). Tensile Testing of thin film microstructures, Proceedings of the SPIE, Vol. 3224, pp. 344-351.

Greek, S., Ericson, F., Johnsson, S., \& Schweitz, J. A. (1997). In situ tensile strength measurement and Weibull analysis of thin film and thin film micromachined polysilicon structures, Thin Solid Films, Vol. 292, pp. 247-254.

Gudmundson, P., \& Wikstrom, A. (2002). Stresses in thin films and interconnect lines, Microelectronics Engineering, Vol. 60, p. 17-29.

Haque, M. A., \& Saif, M. T. A. (2003). A review of MEMS based microscale and nanoscale tensile and bending testing, Experimental Mechanics, Vol. 43, No.3, pp. 248-255.

Haque, M. A., \& Saif, M. T. A. (2004). Deformation mechanisms in free-standing nano-scale thin films: A quantitative in situ transmission electron microscope study, Proceedings of the National Academy of Science, Vol. 101, No. 17, pp. 6335-6340.

He, J., Suo, Z., Marieb, T. N., \& Maiz, J. A. (2004). Electromigration lifetime and critical void volume, Applied Physics Letters, Vol. 85, pp. 4639-4641. 
He, M. Y., Evans, A. G., \& Hutchinson, J. W. (2000). The ratcheting of compressed thermally grown thin films on ductile substrate, Acta Materialia, Vol. 48, pp. 2593-2601.

Hemker, K. J. \& Sharpe, W. N. (2007). Microscale characterization of mechanical properties, Annual Review of Materials Research, Vol. 37, pp. 93-126.

Huang, H., \& Spaepen F. (2000). Tensile testing of free-standing $\mathrm{Cu}, \mathrm{Ag}$, and $\mathrm{Al}$ thin films and Ag/Cu multilayers, Acta Materialia, Vol. 48, pp. 3261-3269.

Huang, M., Suo, Z., \& Ma, Q. (2002). Plastic ratcheting induced cracks in thin film structures, Journal of the Mechanics and Physics of Solids, Vol. 50, pp. 1079-1098.

Knuass, W. G., Chasiotis, I., \& Huang, Y. (2003). Mechanical measurements at the micron and nanometer scales, Mechanics of Materials, Vol. 35, pp. 217-231.

Koskinen, J., Steinwall, J. E., Soave, R., \& Johnson, H. H. (1993). Microtensile testing of freestanding polysilicon fibers of various grain sizes, Journal of Micromechanics and Microengineering, Vol. 3, pp. 13-17.

Larsen, k. P., Rasmussen, A. A., Ravnkilde, J. T., Ginnerup, M., \& Hansen, O. (2003). MEMS device for bending test: measurements of fatigue and creep of electroplated nickel, Sensors and Actuators A, Vol. 103, pp. 156-164.

Lee, H. J., Cornella, G., \& Bravman J. C. (2000). Stress relaxation of free-standing aluminum beams for microelectromechanical systems applications, Applied Physics Letters, Vol. 76, No. 23, pp. 3415-3417.

Lee, H. J., Zhang, P., \& Bravman, J. C. (2003). Tensile failure by grain thinning in micromachined aluminum thin films, Journal of Applied Physics, Vol. 93, No. 3, pp. 1443-1451.

Lee, H. J., Zhang, P., \& Bravman, J. C. (2004). Study on the strength and elongation of freestanding $\mathrm{Al}$ beams for microelectromechanical systems applications, Applied Physics Letters, Vol. 84, No. 6, pp. 915-917.

Lee, H. J., Zhang, P., \& Bravman J. C. (2005). Stress relaxation in free-standing aluminum beams, Thin Solid Films, Vol. 476, pp. 118-124.

Li, K., \& Sharpe, W. N. (1996). Viscoplastic behavior of a notch root at $650^{\circ} \mathrm{C}$ : ISDG measurement and finite element modeling, Journal of Engineering Materials and Technology, Vol. 118, pp. 88-93.

Li, T., \& Suo, Z. (2006). Deformability of thin metal films on elastomer substrates, International Journal of Solids and Structures, Vol. 43, pp. 2351-2363.

Modlinski, R., Witvrouw, A., Ratchev, P., Jourdain, A., Simons, V., Tilmans, H. A. C., Toonder, J. M. J., Puers, R., \& De Wolf, I. (2004). Creep as a reliability problem in MEMS, Microelectronics Reliability, Vol. 44, pp. 1733-1738.

Mulhstein, C. L., Brown, S. B., \& Ritchie, R. O. (2001). High cycle fatigue of single crystal silicon thin films, Journal of Microelectromechanical Systems, Vol. 10, No. 4, pp. 593600 .

Ogawa, H., Suzuki, K., Kaneko, S., Nakano, Y., Ishikawa, Y., \& Kitahara, T. (1997). Measurements of mechanical properties of microfabricated thin films, Proceedings of IEEE Microelectromechanical Systems Workshop, pp. 430-435.

Oh, C. S., \& Sharpe, W. N. (2004). Techniques for measuring thermal expansion and creep of polysilicon, Sensors and Actuators A, Vol. 112, pp. 66-73. 
Oliver, W. C., \& Pharr, G. M. (2004). Measurement of hardness and elastic modulus by instrumented indentation: Advances in understanding and refinements to methodology, Journal of Materials Research, Vol. 19, pp. 3-20.

Park, J. H., Kim, Y. J., \& Choa, S. H. (2006). Mechanical properties of Al-3\%Ti thin films for reliability analysis of RF MEMS switch, Key Engineering Materials, Vol. 306-308, pp. 1319-1324.

Paryab, N., Jahed, H., \& Khajepour, A. (2006). Failure mechanisms of MEMS thermal actuators, Proceedings of the ASME IMECE, Paper no. IMECE2006-15128, pp. 397-406

Rajagopalan, J., Han, J. H., Saif, M. T. H. (2007). Plastic deformation recovery in freestanding nanocrystalline aluminum and gold thin films, Science, Vol. 315, pp. 1831-1834.

Read, D. T., \& Dally, J. W. (1993). A new method for measuring the strength and ductility of thin films, Journal of Materials Research, Vol. 8, No. 7, pp. 1542-1549.

Read, D. T. (1998a). Piezo-actuated microtensile test apparatus, Journal of Testing and Evaluation, Vol. 26, No. 3, pp. 255-259.

Read, D. T. (1998b). Young's modulus of thin film by speckle interferometry, Measurement Science and Technology, Vol. 9, pp. 676-685.

Ruud, J. A., Josell, D., Spaepen, F., \& Greer, A. L. (1993). A new method for tensile testing of thin films, Journal of Materials Research, Vol. 8, No.1, pp. 112-117.

Samuel, B. A., \& Haque, M. A. (2006). Room temperature relaxation of freestanding nanocrystalline gold films, Journal of Micromechanics and Microengineering, Vol. 16, pp. 929-934.

Sharpe, W. N. (1968). The interferometric strain gage, Experimental Mechanics, Vol. 8,No. 4, pp. 164-170.

Sharpe, W. N. (1982). Application of the interferometric strain/displacement gage, Optical Engineering, Vol. 21, No. 3, pp. 483-488.

Sharpe, W. N. (1989). An interferometric strain/displacement measurement system, NASA Technical Memorandum, 101638.

Sharpe, W. N., Yuan, B., \& Edwards, R. L. (1997). A new technique for measuring the mechanical properties of thin films, Journal of Microelectromechanical Systems, Vol. 6, No. 3, pp. 193-199.

Sharpe, W. N., Bagdahn, J., Jackson K., \& Coles , G. (2003). Tensile testing of MEMS materials - recent progress, Journal of Materials Science, Vol. 38, pp. 4075-4079.

Sharpe, W. N., \& Bagdahn, J. (2004). Fatigue testing of polysilicon - A review, Mechanics of Materials, Vol. 36, No. 1-2, pp. 3-11.

Shrotriya, P., Allameh, S. M., \& Soboyejo, W. O. (2004). On the evolution of surface morphology of polysilicon MEMS structures during fatigue, Mechanics of Materials, Vol. 36, pp. 35-44.

Sontheimer, A. B. (2002). Digital Micromirror Device (DMD) hinge memory lifetime reliability modeling, Proceedings of IEEE International Reliability Physics Symposium, pp. 118-121.

Sridhar, N., Srolovitz, D. J., \& Suo, Z. (2001). Kinetics of buckling of a compressed film on a viscous substrate, Applied Physics Letters, Vol. 78, pp. 2482-2484.

Stance, J. R., Smith, C. H., Chasiotis, I., \& Barker, N. S. (2007). Realization of low-stress Au cantilever beams, Journal of Micromechanics and Microengineering, Vol. 17, N7-N10. 
Tajik, A. (2008). An Experimental Technique for the study of the Mechanical Behavior of Thin Film Materials at Micro- and Nano-Scale, MASc Thesis, University of Waterloo.

Tsuchiya, T., Tabata, O., Sakata, J., \& Taga, Y. (1997). Specimen size effect on tensile strength of surface micromachined polycrystalline silicon thin films, Proceedings of IEEE Microelectromechanical Systems, pp. 529-534.

Tsuchiya, T., Tabata, O., Sakata, J., \& Taga, Y. (1998). Specimen size effect on tensile strength of surface micromachined polycrystalline silicon thin films, Journal of Microelectromechanical Systems, Vol. 7, No. 1, pp. 106-113.

Tsui, T. Y., McKerrow, A. J., \& Vlassak, J. J. (2005). Constraint effect on thin film channel cracking behavior, Journal of Materials Research, Vol. 20, pp. 2266-2273.

Tuck, K., Jungen A., Geisberger, Ellis, M., \& Skidmore, G. (2005). A study of creep in polysilicon MEMS devices, Journal of Engineering Materials and Technology, Vol. 127, pp. 90-96.

van Spengen, W. M. (2003). MEMS reliability from a failure mechanisms perspective, Microelectronics Reliability, Vol. 43, pp. 1049-1060.

Vlassak, J. J., \& Nix, W. D. (1992). A new buldge test technique for the determination of Young's modulus and Poisson's ratio of thin films, Journal of Materials Research, Vol. 7, pp. 3242-3249.

Wang, G., Ho, P. S., \& Groothuis, S. (2005). Chip-packaging interaction: a critical concern for $\mathrm{Cu}$ /Low-k packaging, Microelectronics Reliability, Vol. 45, pp. 1079-1093.

Xiang, Y. (2005). Plasticity in Cu thin films: an experimental investigation of the effect of microstructure, PhD Dissertation, Harvard University.

Xiang, Y., Chen, X., \& Vlassak, J. J. (2005). Plane-strain buldge test for thin films, Journal of Materials Research, Vol. 20, pp. 2360-2370.

Yu, D. Y. W. (2003). Microtensile testing of free-standing and supported metallic thin films, PhD Dissertation, Harvard University.

Yu, D. Y. W., \& Spaepen, F. (2004). The yield strength of thin copper films on Kapton, Journal of Applied Physics, Vol. 95, No. 6, pp. 2991-2997.

Yuan, B., \& Sharpe, W. N. (1997). Mechanical testing of polysilicon thin films with the ISDG, Experimental Techniques, Vol. 21, No. 2, pp. 32-35.

Zhang, P., Lee, H. J., \& Bravman, J. C. (2001). Mechanical testing of free-standing aluminum microbeams for MEMS application, in Mechanical Properties of Structural Films, Ed. Mulstein, C. and Brown, S. B., ASTM STP 1413.

Zhu Y., Barthelat, F., Labossiere, P. E., Moldovan, N., \& Espinosa, H. D. (2003). Nanoscale displacement and strain measurement, Proceedings of the SEM Annual Conference on Experimental and Applied Mechanics, paper 155.

Zhu, Y., Ke, C., \& Espinosa, H. D. (2007). Experimental techniques for the mechanical characterization of one-dimensional nanostructures, Experimental Mechanics, Vol. 47, No. 1, pp. 7-24.

Zupan, M. \& Hemker, K. J. (2001). High temperature microsample tensile testing of $\gamma$-TiAl, Materials Science and Engineering A, Vol. 319-321, pp. 810-814.

Zupan, M., Hayden, C., Boehlert, C. J., \& Hemker, K. J. (2001). Development of high temperature microsample testing, Experimental Mechanics, Vol. 41, No. 3, pp. 1-6. 
Zupan, M., \& Hemker, K. J. (2002). Application of Fourier analysis to the laser based interferomteric strain/displacement gage, Experimental Mechanics, Vol. 42, No. 2, pp. 214-220. 


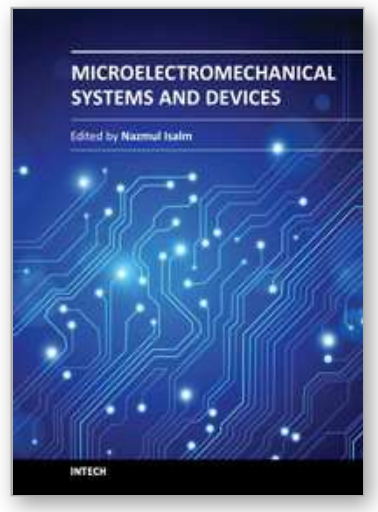

\author{
Microelectromechanical Systems and Devices \\ Edited by Dr Nazmul Islam
}

ISBN 978-953-51-0306-6

Hard cover, 480 pages

Publisher InTech

Published online 28, March, 2012

Published in print edition March, 2012

The advances of microelectromechanical systems (MEMS) and devices have been instrumental in the demonstration of new devices and applications, and even in the creation of new fields of research and development: bioMEMS, actuators, microfluidic devices, RF and optical MEMS. Experience indicates a need for MEMS book covering these materials as well as the most important process steps in bulk micro-machining and modeling. We are very pleased to present this book that contains 18 chapters, written by the experts in the field of MEMS. These chapters are groups into four broad sections of BioMEMS Devices, MEMS characterization and micromachining, RF and Optical MEMS, and MEMS based Actuators. The book starts with the emerging field of bioMEMS, including MEMS coil for retinal prostheses, DNA extraction by micro/biofluidics devices and acoustic biosensors. MEMS characterization, micromachining, macromodels, RF and Optical MEMS switches are discussed in next sections. The book concludes with the emphasis on MEMS based actuators.

\title{
How to reference
}

In order to correctly reference this scholarly work, feel free to copy and paste the following:

Arash Tajik and Hamid Jahed (2012). Standalone Tensile Testing of Thin Film Materials for MEMS/NEMS Applications, Microelectromechanical Systems and Devices, Dr Nazmul Islam (Ed.), ISBN: 978-953-51-0306-6, InTech, Available from: http://www.intechopen.com/books/microelectromechanical-systems-anddevices/standalone-tensile-testing-of-thin-film-materials-for-mems-nems-applications

\section{INTECH}

open science | open minds

\section{InTech Europe}

University Campus STeP Ri

Slavka Krautzeka 83/A

51000 Rijeka, Croatia

Phone: +385 (51) 770447

Fax: +385 (51) 686166

www.intechopen.com

\section{InTech China}

Unit 405, Office Block, Hotel Equatorial Shanghai

No.65, Yan An Road (West), Shanghai, 200040, China

中国上海市延安西路65号上海国际贵都大饭店办公楼 405 单元

Phone: +86-21-62489820

Fax: $+86-21-62489821$ 
(C) 2012 The Author(s). Licensee IntechOpen. This is an open access article distributed under the terms of the Creative Commons Attribution 3.0 License, which permits unrestricted use, distribution, and reproduction in any medium, provided the original work is properly cited. 